\title{
Os jogos de palavras na tradução*
}

\author{
Jeroen Vandaele ${ }^{* *}$ \\ Tradução: Tiago Marques Luiz ${ }^{* * *}$
}

\section{Jogo de palavras e humor}

A definição de jogos de palavras proposta por Dirk Delabastita é compacta, porém abrangente:

Jogo de palavras é o nome geral para os vários fenômenos textuais em que as características estruturais da(s) língua(s) são exploradas para provocar um confronto comunicativamente significativo de duas (ou mais) estruturas linguísticas com formas mais ou menos semelhantes e mais ou menos diferentes significados (DELABASTITA, 1996, p. 128, tradução minha ${ }^{1}$ ).

Do ponto de vista semântico, muitos significados são ativados pelas formas semelhantes ou idênticas. E do ponto de vista da forma, a definição inclui a homonímia (mesmo som e grafia), homofonia (mesmo som), homografia (mesma grafia) e paronimia (forma semelhante). Na vertente textual, o autor acrescenta que um trocadilho pode ser "horizontal" ou "vertical" (HAUSSMANN, explicado em DELABASTITA, 1996, p. 128). O professor de História da Economia em Harvard, Neal Ferguson, oferece um exemplo de um trocadilho vertical: o título de um capítulo de livro sobre a América, "Chimerica". Como título de um capítulo, "Chimerica" é um

\footnotetext{
"Este artigo do professor Vandaele foi publicado como capítulo no segundo volume do livro Handbook of Translation Studies, editado por Yves Gambier e Luc van Doorslaer, publicado pela John Benjamins em 2011. A presente tradução foi autorizada pela Editora John Benjamins (John Benjamins Publishing House, <https://benjamins.com>) e pelo autor Jeroen Vandaele, a quem agradeço imensamente. A referência deste capítulo consta nesta nota, a pedido do setor de Direitos da John Benjamins, como também será referenciado ao final: VANDAELE, Jeroen. Wordplay in Translation. In: GAMBIER, Yves; VAN DOORSLAER, Luc. Handbook of Translation Studies. Volume 2. Amsterdam/Philadelphia: John Benjamins Publishing Company, 2011, p. 180-183. Além do agradecimento ao professor Vandaele, estendo meus agradecimentos ao Professor Luc van Doorslaer, editor da coleção Handbook of Translation Studies, publicada pela John Benjamins, e pelo norteamento para que o trabalho atingisse seu objetivo. E finalmente, à Sra. Ineke Elskamp, coordenadora da Seção de Direitos e Permissões da John Benjamins, que me permitiu realizar a tradução, com a ressalva da devida referência do texto.

***Jeroen Vandaele é Doutor pela Katholieke Universiteit Leuven, e é membro efetivo da equipe acadêmica da Faculdade de Artes da Universidade de Ghent (UGhent), atuando na seção hispânica do Departamento de Tradução, Interpretação e Comunicação. De 2008 a 2017 foi professor de Espanhol na Universidade de Oslo (Noruega). Seus principais interesses de pesquisa são Ideologia em Tradução; Franquismo; Comédia; Humor em Tradução; Poética; Estudos Literários Cognitivos; e Narratologia (incluindo narratologia do cinema).

****Doutorando em Letras pela Universidade Federal de Uberlândia.

${ }^{1}$ Original em inglês: "Wordplay is the general name for the various textual phenomena in which structural features of the language(s) are exploited in order to bring about a communicatively significant confrontation of two (or more) linguistic structures with more or less similar forms and more or less different meanings".
} 
trocadilho vertical, pois vários significados são ativados por uma forma (token) no eixo comunicativo. De uma só vez, o token chimerica se refere à enorme participação da China na economia dos EUA e à palavra chimera. Em trocadilhos horizontais, vários símbolos idênticos ou similares aparecem na cadeia de comunicação para ativar vários significados: "How the US put US to shame" é um exemplo homográfico de Delabastita (DELABASTITA, 1996, p. 129).

O trocadilho Chimerica de Ferguson mostra, de um lado, que o jogo de palavras não é uma subcategoria do humor (cf. HENRY, 2003, p. 36): o trocadilho de Ferguson é muito sério. Por outro lado, os jogos de palavras - talvez até mesmo o trocadilho de Ferguson - geralmente criam alguma diversão, um sorriso ou até mesmo um riso. Se aceitarmos que o humor se enraíza na incongruência e na superioridade, então compreendemos porque o jogo de palavras é muitas vezes visto como humorístico.

$\mathrm{Na}$ verdade, na medida em que nossa ingênua intuição linguística sugere que existe uma correspondência de um-para-um entre as palavras e as coisas, o jogo de palavras pode ser (ingenuamente) percebido como uma incongruência linguística (DELABASTITA, 2004, p. 601); e pragmaticamente (discursivamente), geralmente buscamos o uso não-ambíguo da linguagem (discurso) para que a prática do jogo de palavras possa ser sentida como uma incongruência pragmática (ibid). Além disso, algumas formas de jogo de palavras ativam mecanismos de superioridade: elas requerem que ativemos o conhecimento prévio relevante e nos convidam a encontrar "soluções" interpretativas para comunicação inconsistente (VANDAELE, 2001, p. 38) e que elas podem ser "demonstrações de virtuosidade" (HENRY, 2003, p. 154, tradução minha $^{2}$ ).

\section{Jogos de palavras e tradução}

Seja a sua natureza séria ou cômica, os jogos de palavras criam problemas linguísticos de traduzibilidade, porque línguas diferentes têm diferentes distribuições de formas de significado (DELABASTITA, 2004, p. 601; ver também HENRY, 2003, p. 69-110, para uma longa discussão sobre traduzibilidade).

Delabastita observa que uma dissimilaridade estrutural e tipológica da linguagem fonte e da língua-alvo aumenta a intraduzibilidade linguística dos trocadilhos. Assim, ele também insiste que os trocadilhos são fenômenos textuais que exigem uma solução textual. Uma abordagem textual dos trocadilhos, que não de forma isolada, aumenta a capacidade de tradução. Por exemplo, um trocadilho vertical baseado na polissemia (o espanhol jay! significa tanto um "uau" admirador e um doloroso "ai") pode ser traduzido para o holandês por um horizontal baseado na paronímia (o holandês wauw! e auw!) (VANDAELE, 2010). Além disso, Delabastita argumenta o seguinte: se os tradutores refletirem sobre as várias funções textuais que os trocadilhos podem exercer em um texto, serão capazes de encontrar maneiras ou técnicas para traduzi-las: a tradução pode ir de um trocadilho para outro (como no exemplo do ;ay!), do trocadilho ao não-trocadilho, do trocadilho a um dispositivo retoricamente relacionado, como repetição, aliteração ou rima (DELABASTITA, 1996, p. 134), do trocadilho cômico ao não-trocadilho cômico, etc. Para uma análise nesse sentido, veja, por exemplo, o trabalho de Marco (2010) sobre as traduções catalãs das obras de Oscar Wilde e Graham Swift. Marco observa em seu corpus que "os tradutores tendem a usar técnicas que resultam em uma balança punitiva negativa, ou seja, técnicas que implicam em perda

\footnotetext{
${ }^{2}$ Original em inglês: "demonstrations of virtuosity”. 
em termos de atividade punitiva em relação ao [t]exto-[f]onte" (MARCO, 2010, p. 276, tradução minha ${ }^{3}$ ).

Nessa mesma linha, Klitgård (2005) insiste, em relação ao Ulisses de James Joyce, que os trocadilhos não são apenas itens com funções textuais, mas elementos padronizados com significados contextuais e ideológicos: "Os trocadilhos de Joyce não são apenas diversão verbal e lúdica (...) mas grandes padrões não-familiares e estrangeiros de fortes mensagens políticas, ideológicas ou éticas" (KLITGÅRD, 2005, p. 88, tradução minha ${ }^{4}$ ). Em outras palavras, a importância metalinguística específica de um trocadilho é apenas um fator a ser levado em consideração, cujo peso depende de fatores textuais e contextuais. Por exemplo, se é verdade que jogos de palavras muitas vezes carregam conteúdo socialmente transgressivo, a não-tradução de um trocadilho pode ter fundamentos morais em vez de linguísticos: o que devemos fazer da tradução franquista Con faldas y a lo loco ("Wearing skirts and foolishly") da comédia de Billy Wilder Some Like It Hot $\left(1959^{5}\right)$ ?

Delabastita (1996) introduz uma coleção de excelente de estudos teóricos. Gottlieb (1997) aponta que os trocadilhos nas histórias em quadrinhos e na comédia televisiva são frequentemente ativados por meios "polisemióticos". Outras referências à tradução de jogos de palavras podem ser encontradas em Heibert (1993), Tęcza (1997) e Henry (2003). As considerações teóricas em Delabastita (2004) podem auxiliar os estudantes de tradução a encontrarem soluções práticas bem fundamentadas para jogos de palavras aparentemente impossíveis.

\section{3. É humor linguístico, mas não jogo de palavras?}

Apesar da insistência de Delabastita e de outros pesquisadores de que nem mesmo os jogos de palavras não são intraduzíveis, é óbvio que o humor verbalmente expresso se estende de um continuum desde o humor facilmente traduzível até o humor "metalinguístico" muito resistente (isso se deixamos os aspectos culturais de lado). Vale a pena perguntar se jogar com as palavras, que não é o mesmo que jogar em palavras (ou seja, que não é um jogo de palavras stricto sensu (HENRY, 2003, p. 41)) possa também, em certa medida, ser resistente à tradução.

Para esse efeito, Attardo (1994, p. 223) sugere que a parafraseabilidade intralinguística - e a traduzibilidade interlinguística - são um bom teste para ver se o humor verbalmente expresso é bastante "referencial" (quando sua tradução é fácil) ou "(meta) linguístico" (isto é, se o texto-fonte é resistente). No entanto, Attardo também diminui a importância desse teste, alegando que a maioria das piadas é traduzível ou parafraseável e, portanto, não (meta)linguística.

Antonopoulou (2002) argumenta de forma contrária, que a dependência do humor na língua é difusa, indo muito além do nível sócio e metalinguístico. Para linguistas cognitivos como Antonopoulou e Nikiforidou (2009), a expressão idiomática é onipresente nas línguas, e muito humor é linguístico, no sentido de que depende de construções linguísticas específicas.

Uma perspectiva linguística cognitiva sobre a tradução do humor (ver abordagens cognitivas) pretende oferecer "análises de base refinadas cognitivamente que enfatizam a importância da expressão idiomática (...), como faz a Gramática da

\footnotetext{
${ }^{3}$ Original em inglês: "the translators tend to use techniques resulting in a negative punning balance, i.e. techniques which imply loss in terms of punning activity with regard to the S[ource] T[ext]".

${ }^{4}$ Original em inglês: "Joyce's puns are not just verbal fun and games (...) but form large unfamiliar and foreign patterns of strong political, ideological or ethical messages".

${ }^{5}$ Nota do tradutor - Tradução brasileira: Quanto Mais Quente, Melhor.
} 
Construção" (ANTONOPOULOU, 2002, p. 199, tradução minha ${ }^{6}$ ). Sobre a frase de abertura da obra Trouble is my Business, de Raymond Chandler ("Anna Halsey tinha

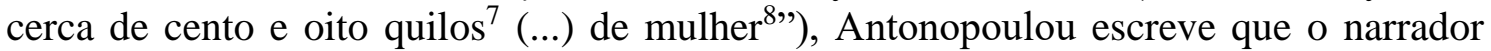
usa uma construção linguística para criar humor (ANTONOPOULOU, 2002, p. 204). O humor depende do substantivo contável de massa $x$ quilos de y combinado com o substantivo mulher. Para os tradutores, é importante perceber que, apesar do humor metalinguístico, muito desse humor é linguístico, no sentido de que explora as normas cognitivas associadas às construções linguísticas. Tais análises explicam como "Anna Halsey era uma mulher que tinha cerca de cento e oito quilos "” não é uma paráfrase humorística; e que "Anna Halsey era una mujer de ciento diez kilos" não é uma tradução engraçada no espanhol.

Há, no entanto, uma tradução em espanhol relativamente fácil e adequada (“Anna Halsey era ciento diez kilos de mujer", e que é engraçada pela mesma razão que o texto fonte (pelo menos para aqueles que podem conviver com o seu significado depreciativo); e este fato mostra que o problema da tradução "linguística" aqui não é causado por uma indisponibilidade linguística de estruturas (isto é, de pares formasignificado na langue espanhola), mas pelo uso incomum feito por Chandler (parole) de estruturas perfeitamente disponíveis. Para os tradutores de espanhol, portanto, a piada do narrador de Chandler claramente não é metalinguística (associada à langue), mas também não é totalmente "referencial" (isto é, totalmente engraçada por causa do que ela representa, não importa como ela a represente): embora não esteja vinculada à langue inglesa, a representação é como certamente importa -e isso é uma questão de brincar com as palavras (embora não nas palavras).

\section{REFERÊNCIAS}

ANTONOPOULOU, Eleni. "A cognitive approach to literary humour devices: translating Raymond Chandler". In: VANDAELE, Jeroen (ed). Translating humour: Special issue of The Translator. Volume 8, n. 2, p. 195-220, 2002.

; NIKIFORIDOU, Kiki 2009. Deconstructing Verbal Humour with Construction Grammar. In: BRÔNE, Geert; VANDAELE, Jeroen (eds). Cognitive Poetics. Berlin: Mouton de Gruyter, 2009, p. 289-314.

ATTARDO, Salvatore. Linguistic theories of humor. Berlin: Mouton de Gruyter. 1994

DELABASTITA, Dirk. There's a Double Tongue: An Investigation into the Translation of Shakespeare's Wordplay, with special reference to Hamlet. Amsterdam: Rodopi, 1993.

\footnotetext{
${ }^{6}$ Original em inglês: "fine-grained, cognitively based analyses which emphasize the importance of idiomaticity (...), as Construction Grammar does".

${ }^{7}$ Nota do tradutor: Em tabela consultada sobre medida de peso, 1 pound $=0,45 \mathrm{~kg}$. Link da tabela de Medicina Intensiva: <https://www.rapidtables.com/convert/weight/pound-to-kg.html>. Acessado em 04 dez. 2018.

${ }^{8}$ Original em inglês: “Anna Halsey was about two hundred and forty pounds of (...) woman”.

${ }^{9}$ Original em inglês: "Anna Halsey was a woman of about two hundred and forty pounds".
} 
Introduction. In: DELABASTITA, Dirk. Wordplay and Translation: Essays on Punning and Translation, Special issue of The Translator, volume 2, n. 2, p. 1-22, 1996.

. Wordplay as a translation problem: a linguistic perspective. In: KITTEL, Harald; FRANK, Armin Paul; GREINER, Norbert; HERMANS, Theo; KOLLER, Werner; LAMBERT, José; PAUL, Fritz (eds). Übersetzung, translation, traduction. Berlin: Mouton de Gruyter, 2004, p. 600-606.

GOTTLIEB, Henrik. You got the picture? On the polysemiotics of subtitling wordplay. In: DELABASTITA, Dirk (ed). Traductio: essays on punning and translation. New York: Routledge, 1997, p. 207-232.

HEIBERT, Frank. Das Wortspiel als Stilmittel und seine Übersetzung am Beispiel von sieben Übersetzungen des 'Ulysses' von James Joyce. Tübingen: Narr, 1993.

HENRY, Jacqueline. La traduction des jeux de mots. Paris: Presses de la Sorbonne Nouvelle, 2003.

KLITGÅRD, Ida. Taking the pun by the horns: the translation of wordplay in James Joyce's Ulysses. Target, vol. 17, n. 1, p. 71-92, 2005.

MARCO, Josep. The translation of wordplay in literary texts. Typology, techniques and factors in a corpus of English-Catalan source text and target text segments. Target, volume 22, n. 2, p. 264-297, 2010.

TĘCZA, Zygmunt. Das Wortspiel in der Übersetzung. Stanislaw Lems Spiele mit dem Wort als Gegenstand interlingualen Transfers. Tübingen: Niemeyer, 1997.

VANDAELE, Jeroen. Si sérieux s'abstenir: le discours sur l'humour traduit. Target, volume 13, n. 1, p. 29-44, 2001.

Spaanse humor vertalen. Idioma. Revue de linguistique et de traductologie, volume 20, p. 189-200, 2010.

. Wordplay in Translation. In: GAMBIER, Yves; VAN DOORSLAER, Luc. Handbook of Translation Studies. Volume 2. Amsterdam/Philadelphia: John Benjamins Publishing Company, 2011, p. 180-183.

Data de envio: 10-10-2018

Data de aprovação: 06-12-2018

Data de publicação: 17-12-2018 